\title{
Effectiveness of an individual, online e-learning program about sexually transmitted infections: a prospective cohort study
}

Linda H. A. Bos-Bonnie ${ }^{1 *}$, Jan E. A. M. van Bergen², Ellen te Pas ${ }^{3}$, Michael A. Kijser ${ }^{4}$ and Nynke van Dijk ${ }^{1}$

\begin{abstract}
Background: Primary health-care professionals play an important role in the treatment and prevention of Sexually Transmitted Infections (STI). Continuing Medical Education (CME)-courses can influence the knowledge and behavior of health-care professionals concerning STI. We performed a prospective cohort study to evaluate if the individual and online e-learning program "The STI-consultation", which uses the Commitment-to-Change (CtC)method, is able to improve the knowledge, attitude and behavior of Dutch General Practitioners (GPs), concerning the STI-consultation. This e-learning program is an individual, accredited, online CME-program, which is freely available for all GPs and GP-trainees in the Netherlands.
\end{abstract}

Methods: In total 2192 participants completed the questionnaire before completing the e-learning program and 249 participants completed the follow-up questionnaire after completing the e-learning program. The effect of the program on their knowledge, attitude and behavior concerning the STI-consultation was evaluated.

Results: In total 193 participants formulated 601 learning points that matched the learning objectives of the program. The knowledge and attitude of the participants improved, which persisted up to two years after completing the program. Another 179 participants formulated a total of 261 intended changes concerning the sexual history taking, additional investigation and treatment of STI, $97.2 \%$ of these changes was partially or fully implemented in daily practice. Also, 114 participants formulated a total of 180 "unintended" changes in daily practice. These changes concerned the attitude of participants towards STI and the working conditions concerning the STI-consultation.

Conclusion: The individual, online e-learning program "The STI-consultation", which uses the CtC-method, has a small but lasting, positive effect on the knowledge, attitude, and behavior of GPs concerning the STI-consultation.

Keywords: Education, Medical, Continuing [MeSH], E-learning program, Sexually Transmitted diseases [MeSH]

\section{Background}

Since the incidence of sexually transmitted infections (STI) is rising, the pressure on health-care systems is increasing and the health of many (young) people is at risk [1-4]. Primary health-care professionals therefore, have to be able to provide sufficient care to patients who are at risk for, or suffer from, STI [5]. However, investigation among primary care physicians has shown that

\footnotetext{
* Correspondence: I.h.bos@amc.uva.nl

${ }^{1}$ Department of General Practice, Academic Medical Centre-University of Amsterdam, Meibergdreef 9, Amsterdam 1105 AZ, The Netherlands Full list of author information is available at the end of the article
}

few health-care professionals regularly take a sexual history form their patients, and that these histories rarely provide sufficient information for an appropriate diagnostic process, treatment and sexual education and counseling [6].

The knowledge and behavior of general practitioners (GPs) concerning STI can be influenced by continuing medical education (CME)-programs [7]. The goal of CME is to improve the knowledge and competencies of health-care professionals and to change their behavior in daily practice. To achieve these improvements, there has been an increasing interest in the improvement of the 
quality and effectiveness of CME [8]. Additionally, next to the traditional, offline forms of CME, like lectures and workshops, the use of online CME-courses (e-learning), using the internet and other electronic media to transfer educational programs, is increasing [8-12]. The advantage of e-learning programs for CME over traditional forms of CME is that they are flexible. Courses can be accessed whenever and wherever wanted, and they can be adapted to the entrance-level of the participant [8]. E-learning programs for CME have shown to achieve an enduring increase in knowledge, and induce changes in behavior [9].

To achieve a behavioral change following a CMEcourse, the Commitment-to-Change (CtC)-method seems a useful addition [13-15]. In the study performed by Domino and colleagues it was suggested that the use of the CtC-method in a CME-course was more likely to induce a behavioural changes than a CME-course not using the CtC-method [13]. Additionally, Pereles and colleagues suggest that the behavioural changes made in reaction to the $\mathrm{CtC}$-method sustained over a longer period of time [15]. The CtC-method stimulates the translation from education to daily practice by focusing on personal plans for behavioral change. One to one-and-a half month after completing the CME-course, participants are reminded of their intended change and asked whether they have changed their practice. It is this change of behavior that is the pursued outcome of the CtC-method [16]. The reminder can be presented to the participants both orally or in writing.

To date, little attention has been devoted to the effect of the CtC-method in e-learning programs. Although elearning programs for $\mathrm{CME}$ are able to improve knowledge and induce changes in behavior [9], there are still are doubts on the role of online CME-courses and the effectiveness of self-directed learning [8]. Additionally, the $\mathrm{CtC}$-method has only been studied in traditional, offline CME-courses [13-15].

When intending to improve the knowledge concerning STI and the sexual history taking-behavior of health-care professionals, a behavioral change has to be achieved. The aim of the present paper is to evaluate if the individual, online e-learning module "The STI-consultation", using the $\mathrm{CtC}$-method, has a lasting, positive effect on the knowledge, attitude, and behavior of GP's concerning the STI-consultation.

\section{Methods}

\section{Context}

In the Netherlands, GPs perform 270,000 STI-consultations per year, accounting for $70 \%$ of the STI-consultations $[17,18]$. CME for Dutch GPs is offered by the Dutch College of GPs (NHG), which develops and manages guidelines and individual CME-programs, and organizes
CME-meetings ten times a year [19]. The CME-programs of the NHG are accessible by all GP's and GP-trainees in the Netherlands. New CME-programs are promoted by email, by mail, and via the website of the NHG.

\section{Intervention}

The individual e-learning program "The STI-consultation", which uses the CtC-method, was created by the NHG in co-operation with the Dutch expertise-center "STI-aids Netherlands" and the department of General Practice of the Academic Medical Centre-University of Amsterdam. The content e-learning program was based on the content of the NHG-guideline "The STI-consultation" [20]. The elearning program "The STI-consultation" was constructed using the "Competence profile and attainment targets for GPs" [21-23], which is based on the CanMEDS competency framework [23, 24]. The specific learning objectives for the program per competence area are presented in a separate file [see Additional file 1: Learning objectives for the e-learning program "The STI-consultation", presented per competence-area.]. The e-learning program is available from the website of the NHG since September 2013. It is freely available to all 12,500 Dutch GPs and GP-trainees, participation in the e-learning program is voluntary. Completing the e-learning program "The STI-consultation" takes about two hours and participants can decide themselves whether they choose to complete the e-learning program in one time or in different attempts. CME-credits will be awarded after the full completion of the e-learning program [25].

Changing the behavior of health-care professionals in daily practice requires three stages of change: confrontation with activities that trigger the consideration of change (priming), experiencing strategies to motivate or facilitate the change (focusing), and maintaining the behavioral change by means of a supportive activity (follow-up) [26-28]. The e-learning program "The STIconsultation" uses various didactic methods to meet the learning objectives of the program and to achieve a behavioral change [21]. The didactic methods of interest in this study were the quickscan (priming), the short and interactive videotaped case-studies with examples of good and less appropriate behavior (priming and focusing) and the CtC-method (follow-up). The questions in the quickscan concerned the knowledge and attitude of participants towards the STI-consultation. The questions used in the quickscan are presented in an additional file [see Additional file 2: English-language version of the questionnaire used in the study]. They were based on the NHG-guideline [29], and on difficulties that GPs experienced during a STI-consultation, obtained by means of a focus group among GPs. The quickscan was both used for triggering the consideration of change (priming) and to evaluate the effect of the e-learning program on 
the knowledge and attitude of participants about STI. The videotaped case-studies were used to introduce a role model for the GPs. Role models are persons who a learner can identify with, who are in a position that the learner wants to be in, and master skills that the learner wants to master. Role models are able to influence the attitudes and behavior of learners [30-32]. The CtCmethod asked participants which change they intended to make as a result of what they had learned in the CME-course. After completing the CME-course, participants were reminded of their intended change two times by e-mail and they were asked if they had implemented the intended change in their daily practice [16]. In order to evaluate the effect of the e-learning program on the knowledge, attitude, and behaviour of participants over time, we compared the results of participants that completed the e-learning program more than one year ago to the results of the participants that completed the elearning program one year ago or less.

\section{Study population and data collection}

The e-learning program "The STI-consultation" was freely accessible for all Dutch GPs to allow the full population of GPs to participate in the study. The data for this project were collected among GPs that had completed the program. Data were collected since the elearning program became available in September 2013 and the data-collection was completed in September 2015. In total 2387 GPs completed the e-learning program, 2203 participants gave permission to collect their data (Fig. 1, Flowchart of the selection of participants). Eleven participants had to be excluded because of missing data, so the data of 2192 participants were used for analysis. Table 1 shows the characteristics of the participants. The mean age of the participants was 38.9 $(+/-9.7)$ years, $14.8 \%$ was GP-trainee. The mean time since the completion of the e-learning module was 18.2 $(+/-5.8)$ months.

Participants were asked about their knowledge and attitude towards STI by means of the 11-question quickscan. The answers were given on a 4-point Likert-scale, ranging from "does not apply" (1) to "very applicable" (4). After completing the program, participants were asked to indicate their three most important learning points and their intended change for daily practice both in reaction to what they had learned in the e-learning program.

Two years after the introduction of the e-learning program, in October 2015, participants received an evaluation questionnaire. In total 287 participants completed

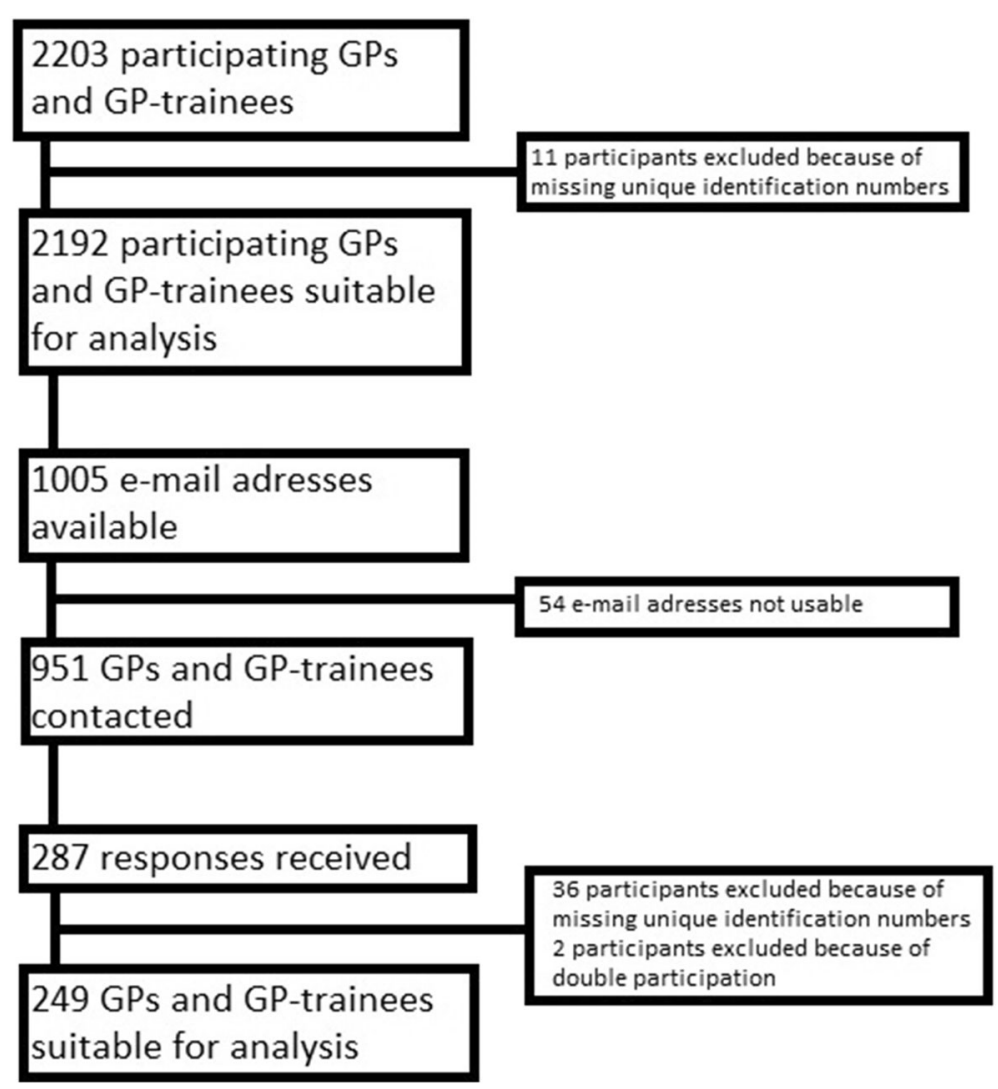

Fig. 1 Flowchart of the selection of participants 
Table 1 Basic characteristics of participants who completed the e-learning program "The STI-consultation"

\begin{tabular}{|c|c|c|}
\hline Characteristic & Number & Percentage \\
\hline \multicolumn{3}{|l|}{ Age } \\
\hline \multicolumn{3}{|l|}{ Mean 38.9+/-9.7 year } \\
\hline$<30$ year & 178 & $10.8 \%$ \\
\hline 30-39 year & 869 & $52.3 \%$ \\
\hline 40-49 year & 313 & $18.9 \%$ \\
\hline 50-59 year & 228 & $13.8 \%$ \\
\hline 60-64 year & 47 & $2.8 \%$ \\
\hline$>65$ year & 19 & $1.1 \%$ \\
\hline \multicolumn{3}{|l|}{ Gender } \\
\hline Male & 624 & $33.6 \%$ \\
\hline Female & 1234 & $66.4 \%$ \\
\hline \multicolumn{3}{|l|}{ Duration of GP-career } \\
\hline GP-trainee & 161 & $14.8 \%$ \\
\hline $0-5$ year & 467 & $42.9 \%$ \\
\hline 5-10 year & 147 & $13.5 \%$ \\
\hline 10-15 year & 110 & $10.1 \%$ \\
\hline$>15$ year & 203 & $18.7 \%$ \\
\hline \multicolumn{3}{|l|}{ Work area } \\
\hline Big city & 310 & $28.5 \%$ \\
\hline Medium-big city & 331 & $30.4 \%$ \\
\hline Small city or rural area & 447 & $41.1 \%$ \\
\hline \multicolumn{3}{|c|}{ Duration since e-learning program was completed } \\
\hline \multicolumn{3}{|l|}{ Mean $18.2+/-5.8$ months } \\
\hline $0-6$ months & 143 & $8.6 \%$ \\
\hline 7-12 months & 227 & $13.7 \%$ \\
\hline 13-18 months & 362 & $21.9 \%$ \\
\hline $18-24$ months & 922 & $55.7 \%$ \\
\hline
\end{tabular}

this questionnaire, 36 participants had to be excluded because of missing data and two participants had to be excluded because of double participation. The responses of 249 (11.4\% of original study population) participants were used for analysis. The questionnaire again contained the eleven questions from the quickscan. Participants who formulated intended changes were asked to what extent they had succeeded to implement their intended changes in daily practice. Participants were also asked if they had implemented any "unintended" changes in daily practice. These "unintended" changes were defined as changes that participants made in daily practice in reaction to what they had learned during the elearning program, without the intention of making the particular change directly after completing the elearning program. The intended changes and the "unintended" changes were compared to evaluate whether the content of the changes differed.

\section{Data analysis}

To evaluate if completing the e-learning program contributed to a change in the knowledge and attitude of participants towards STI, before - and after-scores on the quickscan were compared. To evaluate if scores changed over time since completing the program we compared groups based on time since completing the program (more than one year ago, or one year ago and less).

The learning points, intended changes and implemented changes in daily practice were analyzed by matching them to the specific learning objectives of the e-learning program [see Additional file 1: Learning objectives for the elearning program "The STI-consultation", presented per competence-area.]. If a learning point or change was matched to more than one learning objective, multiple learning points or changes were counted. The matching was done by one researcher (LBB) and checked by another $(\mathrm{NvD})$.

For normally distributed, continuous variables the mean (+/- standard deviation) was calculated. Differences in means between different groups were analyzed by means of ANOVA with the post-hoc Bonferronimethod. Differences in scores over time, were analyzed using the paired sample $T$-test. Nominal values are displayed in cross tables and analyzed using the chi-square test. A $p$-value of $<0.05$ was considered statistically significant.

Because of the high amount of non-responders in the study we only analyzed the data available to us.

All statistical analyses were performed using SPSS version 22 [33].

\section{Results}

Knowledge and attitude towards STI

Table 2 shows change on the questions of the quickscan before and after the completing of the e-learning program. Participants showed a statistically significant increase on 5 of the 11 questions. These questions concerned the sexual history taking when patients presented with questions concerning STI, the feeling of competence regarding the STI-consultation, the STI-testing policy in patients under the age of 25 years, the consideration of the diagnosis of HIV in patients with flu-like symptoms, and the persuasion of an active investigation policy in the GP-practice towards HIV-infections.

There were no significant differences present between participants who completed the e-learning program less than one year ago and participants who completed the elearning program more than one year ago (data not shown).

\section{Formulated learning points after completing the e- learning program}

Of the 2203 participants who completed the e-learning program, 193 participants (8.8\%) together formulated a 
Table 2 Mean Likert-scores on the questions about knowledge and attitude towards STI ( $N=246)$

\begin{tabular}{|c|c|c|c|c|}
\hline Moment of answering the questions & $\begin{array}{l}\text { Before the e-learning program } \\
\text { (Likert }(\text { Mean(SD))) }\end{array}$ & $\begin{array}{l}\text { After the e-learning program } \\
\text { (Likert (Mean(SD))) }\end{array}$ & $\begin{array}{l}\text { Mean difference } \\
\text { (95\% confidence interval) }\end{array}$ & $p$-value \\
\hline \multicolumn{5}{|l|}{ Questions } \\
\hline \multicolumn{5}{|c|}{ I always ask for sexual behavior when a patient presents with questions concerning STI } \\
\hline & $3.5(+/-0.6)$ & $3.6(+/-0.6)$ & $0.10(0.01-0.19)$ & $0.034^{\mathrm{a}}$ \\
\hline \multicolumn{5}{|c|}{ I always ask for sexual behavior when a patient presents with STI-related complaints } \\
\hline & $3.6(+/-0.5)$ & $3.6(+/-0.6)$ & $-0.05(-0.13-0.03)$ & 0.202 \\
\hline \multicolumn{5}{|c|}{ I find it easy to ask open questions about sexual behaviour } \\
\hline & $3.2(+/-0.6)$ & $3.3(+/-0.6)$ & $0.05(-0.04-0.14)$ & 0.240 \\
\hline \multicolumn{5}{|c|}{ I find it difficult to discuss STI in patients with another cultural background } \\
\hline & $2.3(+/-0.8)$ & $2.4(+/-0.7)$ & $0.08(-0.04-0.20)$ & 0.180 \\
\hline \multicolumn{5}{|c|}{ When presenting with questions concerning contraception, I always give information about STI and safe sex } \\
\hline & $3.6(+/-0.6)$ & $3.6(+/-0.7)$ & $-0.00(-0.09-0.08)$ & 0.919 \\
\hline \multicolumn{5}{|c|}{ When presenting for traveler advice, I always give information about STI and safe sex } \\
\hline & $1.8(+/-0.9)$ & $1.8(+/-0.9)$ & $0.00(-0.13-0.14)$ & 0.947 \\
\hline \multicolumn{5}{|c|}{ I feel competent enough to diagnose and treat STI } \\
\hline & $3.5(+/-0.5)$ & $3.6(+/-0.5)$ & $0.10(0.02-0.18)$ & $0.011^{a}$ \\
\hline \multicolumn{5}{|c|}{ I only test for chlamydia in people $<25$ years of age with no risk factors } \\
\hline & $2.6(+/-1.1)$ & $3.0(+/-1.0)$ & $0.37(0.22-0.53)$ & $<0.001^{\mathrm{a}}$ \\
\hline \multicolumn{5}{|c|}{ When presenting with flu-like symptoms, I consider the diagnosis of HIV } \\
\hline & $1.6(+/-0.8)$ & $2.0(+/-0,9)$ & $0.34(0.22-0.46)$ & $<0.001^{\mathrm{a}}$ \\
\hline \multicolumn{5}{|c|}{ I pursue an active investigation policy towards chlamydia-infections in the GP-practice } \\
\hline & $2.4(+/-0.9)$ & $2.5(+/-0.8)$ & $0.06(-0.07-0.20)$ & 0.361 \\
\hline \multicolumn{5}{|c|}{ I pursue an active investigation policy towards HIV-infections in the GP-practice } \\
\hline & $1.9(+/-0.9)$ & $2.1(+/-0.8)$ & $0.22(0.09-0.35)$ & $0.001^{a}$ \\
\hline
\end{tabular}

aStatistically significant differences present

total of 601 learning points. Most learning points concerned sexual history taking (28.1\%), additional investigation $(27.5 \%)$, and the treatment of patients with STI (17.5\%) (Table 3).

Didactic methods most frequently used to formulate learning points were the videotaped case-studies and the quickscan. There were no statistically significant differences in knowledge and attitude between participants who did formulate learning points and participants who did not formulate learning points after completing the elearning program (data not shown).

\section{Changes in daily practice}

In total 179 participants (8.2\%) intended to make a total of 261 changes in daily practice (Table 4). Most intended changes concerned the performance of additional investigation (42.5\%), the sexual history taking (37.4\%), and the treatment of STI (3.8\%).

Participants that formulated intended changes, reported that $34.3 \%$ of the intended changes was fully implemented, $62.9 \%$ was partially implemented, and
$2.8 \%$ was not implemented. Reasons for partially or not implementing the intended changes concerned forgetting the intended changes (50.0\%), small amount of consultation for STI in daily practice (21.4\%), time pressure (14.3\%), shame or resistance to talk about STI (7.1\%), and the costs of STI-tests (7.1\%).

In total 114 participants made a total of 180 "unintended" changes in daily practice. These changes mostly concerned the sexual history taking (41.7\%), the additional investigation (31.7\%), and a change in the working conditions of the STI-consultation (9.4\%). Participants described the change in the working conditions concerning the STI-consultation, as:

"I do not make a phone-call anymore when a patient has a question about STI, but I want to see the patient in my office, so I can more easily ask the right questions." (participant)

"We extended the duration of a STI-consultation from 20 minutes to 30 minutes. Quality-improvement!" (participant) 
Table 3 Amount of formulated learning points per competence area and per learning objective

\begin{tabular}{|c|c|c|c|}
\hline Competence area & Content of learning objectives & Total amour & g points $(\mathrm{N}(\%))$ \\
\hline \multirow[t]{7}{*}{ 1. Medical Expert Role } & & $494(82.2 \%)$ & \\
\hline & Sexual history taking & & $169(28.1 \%)$ \\
\hline & Epidemiology & & $49(8.2 \%)$ \\
\hline & Physical examination & & $4(0.7 \%)$ \\
\hline & Additional investigation & & $165(27.5 \%)$ \\
\hline & Evaluation & & $1(0.2 \%)$ \\
\hline & Treatment & & $106(17.6 \%)$ \\
\hline \multirow[t]{2}{*}{ 2. Communicator Role } & & $18(3.0 \%)$ & \\
\hline & Communication with patient & & $18(3.0 \%)$ \\
\hline \multirow[t]{3}{*}{ 3. Collaborator Role } & & $8(1.3 \%)$ & \\
\hline & Local working arrangements & & $7(1.2 \%)$ \\
\hline & Warning of the partner & & $1(0.2 \%)$ \\
\hline 4. Manager Role & & $0(0.0 \%)$ & \\
\hline \multirow[t]{4}{*}{ 5. Health Advocate Role } & & $48(8.0 \%)$ & \\
\hline & Sexual education & & $9(1.5 \%)$ \\
\hline & Offering investigation for STI & & $2(0.3 \%)$ \\
\hline & Cost-conscious working & & $37(6.2 \%)$ \\
\hline \multirow[t]{2}{*}{ 6. Scholar Role } & & $22(3.7 \%)$ & \\
\hline & Test proporties & & $22(3.7 \%)$ \\
\hline \multirow[t]{4}{*}{ 7. Professional Role } & & $11(1.8 \%)$ & \\
\hline & Medical ethics & & $3(0.5 \%)$ \\
\hline & Engagement with patient & & $2(0.3 \%)$ \\
\hline & Attitude in sexual history taking & & $6(1.0 \%)$ \\
\hline Remaining learning points & & $0(0.0 \%)$ & \\
\hline Total amount of learning points & & 601 & \\
\hline
\end{tabular}

\section{Discussion}

\section{Summary}

This study shows that the individual online e-learning program "The STI-consultation", which uses the CtCmethod, is able to positively influence the knowledge, attitude, and behaviour of GPs concerning the STIconsultation. This positive influence remains up to two years after completing the e-learning program. Participants also noted that the e-learning program had a lasting influence on their knowledge: "It was an interesting CME-course, and it seems like much information has stayed with me."(participant).

Our results indicate that after completing the program, the knowledge and attitude of participants improved and that they changed their behaviour, both by means of intended and "unintended" changes. Remarkable is the finding that, although the amounts are small, the "unintended" changes relatively often concern the working conditions of the STI-consultation and the attitude of participants towards sexuality, STI and sexual history taking, when compared to the intended changes, such as became clear from this remark: "In sexual history taking, I try to focus more on the sexual behavior of the patient, instead of asking if a patient is homosexual (behavior versus identity)". (participant).

\section{Comparison with existing literature}

Our findings suggest that, next to the traditional forms of CME, individual and online forms are effective in improving STI-knowledge and attitudes of health-care professionals. This supports the findings of previous research on the effectivity of internet-based CME and CME for STI [7, 9]. Since health-care professionals, also in our study, still feel resistance to talk about STI or to take a sexual history [34-36], offering an individual e-learning program that participants can complete in their own environment and at their own pace [37], may take away a barrier for completing a CME course on STI, thereby offering the opportunity to improve the knowledge, attitude, and behaviour of health-care professionals concerning the STI-consultation. 
Table 4 Changes in daily clinical practice per competence area and per learning objective

\begin{tabular}{|c|c|c|c|}
\hline Competence area & Content of the learning objective & $\begin{array}{l}\text { Total amount of formulated } \\
\text { intended changes }(\mathrm{N}(\%))\end{array}$ & $\begin{array}{l}\text { Total amount of implementec } \\
\text { "unintended" changes }(\mathrm{N}(\%))\end{array}$ \\
\hline \multirow[t]{7}{*}{ 1. Medical Expert Role } & & $223(85.4 \%)$ & $142(78.9 \%)$ \\
\hline & Sexual history taking & 99 (37.9\%) & 75 (41.7\%) \\
\hline & Epidemiology & $3(1.1 \%)$ & $1(0.6 \%)$ \\
\hline & Physical examination & $0(0.0 \%)$ & $1(0.6 \%)$ \\
\hline & Additional investigation & $111(42.5 \%)$ & $57(31.7 \%)$ \\
\hline & Evaluation & $0(0.0 \%)$ & $3(.7 \%)$ \\
\hline & Treatment & $10(3.8 \%)$ & $5(2.8 \%)$ \\
\hline \multirow[t]{3}{*}{ 2. Communicator Role } & & $6(2.3 \%)$ & $3(1.7 \%)$ \\
\hline & Communication with patient & $6(2.3 \%)$ & $2(1.1 \%)$ \\
\hline & Counceling & $0(0.0 \%)$ & $1(0.6 \%)$ \\
\hline \multirow[t]{4}{*}{ 3. Collaborator Role } & & $5(1.9 \%)$ & $2(1.1 \%)$ \\
\hline & Local working arrangements & $0(0.0 \%)$ & $1(0.6 \%)$ \\
\hline & Referral for specialistic treatment & $3(1.1 \%)$ & $0(0.0 \%)$ \\
\hline & Warning of the partner & $2(0.8 \%)$ & $1(0.6 \%)$ \\
\hline \multirow[t]{2}{*}{ 4. Manager Role } & & $7(2.7 \%)$ & $2(1.1 \%)$ \\
\hline & Testing materials & $7(2.7 \%)$ & $2(1.1 \%)$ \\
\hline \multirow[t]{5}{*}{ 5. Health advocate Role } & & $10(3.8 \%)$ & $8(4.4 \%)$ \\
\hline & Sexual education & $4(1.5 \%)$ & $5(2.8 \%)$ \\
\hline & Offering investigation for STI & $0(0.0 \%)$ & $1(0.6 \%)$ \\
\hline & Awareness of the impact of STI & $1(0.4 \%)$ & $0(0.0 \%)$ \\
\hline & Cost-conscious working & $5(1.9 \%)$ & $2(1.1 \%)$ \\
\hline \multirow[t]{2}{*}{ 6. Scholar Role } & & $3(1.1 \%)$ & $3(1.7 \%)$ \\
\hline & Test proporties & $3(1.1 \%)$ & $3(1.7 \%)$ \\
\hline \multirow[t]{3}{*}{ 7. Professional Role } & & $1(0.4 \%)$ & $3(1.7 \%)$ \\
\hline & Attitude towards sexuality and STI & $1(0.4 \%)$ & $1(0.6 \%)$ \\
\hline & Attitude in sexual history taking & $0(0.0 \%)$ & $2(1.1 \%)$ \\
\hline \multirow[t]{3}{*}{ Remaining formulated intended changes } & & $6(2.3 \%)$ & $17(9.4 \%)$ \\
\hline & Change in working conditions STI-consultation & $4(1.5 \%)$ & $17(9.4 \%)$ \\
\hline & Study NHG-guideline "The STI-consultation" & $2(0.8 \%)$ & $0(0.0 \%)$ \\
\hline Total amount of changes & & 261 & 180 \\
\hline
\end{tabular}

Chi-square test: 15.2, p-value: 0.03

The videotaped case-studies are an important feature of the e-learning program. Previous research shows that both the use of the movies or videotaped case-studies and role models are able to contribute to the process of acquiring knowledge and changing attitude [31, 38, 39]. This might especially hold for programs concerning STI, since a videotaped case-study with a role model can show that, when treating a patient in an open, respectful, and unbiased manner, questions concerning the sexual behaviour of the patients are accepted and answered by the patient. The participants also considered the videotaped case-studies to be important for the e-learning program: "The videotaped case-studies are a nice way to support the sexual history taking of doctors." (participant).

In this study we have also seen that participants formulated intended changes for daily practice, of which $97.2 \%$ was partly or fully implemented in daily practice. This does not only support the findings of previous research performed on the use of the $\mathrm{CtC}$-method in traditional CME-courses [13-15], but it also indicates that the CtCmethod might be effective in individual online CMEcourses. Interestingly, participants also made changes without intending to make that particular change in advance. This phenomenon may be explained by individual differences in the priming-stage of the process of making 
an change in daily practice. In the priming-stage, a certain degree of dissatisfaction with the events in daily practice has to emerge in order to be able to make a change in daily practice. Not every person recognizes or accepts the signals of dissatisfaction at the same time, leading to individual differences in the process of change in daily practice [28]. This is confirmed by the content of these "unintended" changes, which are more frequently related to changes in the working conditions concerning the STIconsultation and the attitude of the participants towards STI and sexual behaviour. The latter may be explained by the theory that a change in professional behaviour or attitude can only take place when one recognizes the impact of the specific behaviour or attitude on others [40], leading to a change whenever a person again is confronted with the particular situation.

\section{Strengths}

Our study is performed in a large study population of over 2000 GPs. Additionally, we were able to analyze the effect of the e-learning program up to two years after the program was completed, showing that changes induced by individual e-learning can have a long-term effect.

\section{Limitations}

Our study is limited by the use of self-reported data of the participants, possibly leading to socially desirable answers. Especially the self-reported data on behavioural changes in daily practice may be subject to self-report bias, leading to the under-report of behaviour that may be considered as non-desirable by the participants and over-report of behaviour that may be considered as desirable by participants [41]. Additionally, the response-rate for the evaluation questionnaire was low, leading to a considerable amount of missing data and a possible overestimation of the studyresults. This low response-rate may be the effect of a few of the disadvantages of e-learning programs, like the lack of social interaction between participants and confusion or frustration as a result of the use of a new and unknown technique [37]. However, analysis of the basic characteristics shows that there are no statistically significant differences between the participants who did respond to the evaluation questionnaire and participants who did not respond to the evaluation questionnaire. It seems that the participants who did respond to the evaluation questionnaire are a good representation of the original study population. Another limitation in our study is the small effect-size in the results of the quickscan. This may be caused by the fact that only a 4-point Likert-scale was used, and by the fact that some of the scores on the questionnaire were already very high before the start of the program. Because we did not use a control group, it is not possible to determine whether the effects we found can be fully attributed to the e-learning program. We are not informed on additional CME-courses that participants followed and the effect of experiences in daily practice on knowledge, attitude and behaviour are difficult to determine.

\section{Implications for education and research}

Our results provide insight in the effectiveness of individual, online CME-courses. Since online CME-courses are gaining popularity $[8,9]$, it is important to gain more knowledge on their efficacy. Future research could benefit from an intensive comparison of online, individual CMEcourses and traditional CME-courses, especially on the STI-consultation, to further determine the role that could be awarded to individual, online CME-courses. Additionally, we could benefit from the use of a control group, non-self-reported data, more detailed response-options for the participants, and a more intensive follow-up procedure to gain more insight in the effects of (components of) individual, online CME-courses on the knowledge, competences, and the behaviour in daily practice of health-care professionals.

\section{Conclusion}

Individual e-learning programs, especially with the addition of CTC, are an effective method for CME, not only for improving and maintaining the knowledge and attitude of health-care professionals, but also for improving their behaviour in daily practice. By offering an individual e-learning program that participants can complete in their own environment and at their own pace, a barrier for completing a CME course on STI may be taken away, also offering the opportunity to improve the knowledge and attitude of the health-care professional concerning STI and sexual history taking.

\section{Additional files}

Additional file 1: Learning objectives for the e-learning program "The STIconsultation", presented per competence-area (translated from Dutch). This file contains the learning objectives for the e-learning program "The STI-consultation", presented per competence-area. The content of this file was based on the "Program plan e-learning "The STIconsultation" (Programmaplan PIN "Het soa-consult"). (DOCX 23 kb)

Additional file 2: English-language version of the questionnaire used in the study (translated from Dutch). This file contains the English-language version of the questionnaire used in the study. The content of this file was translated from the original questionnaire used in our study. (DOC $27 \mathrm{~kb}$ )

\section{Abbreviations}

CME: Continuing Medical Education; CtC: Commitment-to-Change; GP: General Practitioner; NHG: Dutch College of General Practitioners (Nederlands Huisartsen Genootschap); STI: Sexually Transmitted Infections

\section{Acknowledgements}

We would like to thank all the participating GPs and GP-trainees for their efforts on completing the e-learning program and the evaluation questionnaire. We would like to thank "Soa Aids Nederland" (STI Aids Netherlands) for their contribution to this research project. 


\section{Funding}

For the development and distribution of the e-learning "The STDconsultation" an unrestricted grant was received from "Soa Aids Nederland" (STI Aids Netherlands). "Soa Aids Nederland" is a Dutch NGO and Expertise Centre for STI.

\section{Availability of data and materials}

The data that support the findings of this study are available from the Dutch College of General Practitioners but restrictions apply to the availability of these data, which were used under license for the current study, and so are not publicly available. Data are however available from the authors upon reasonable request and with permission of the Dutch College of General Practitioners.

\section{Authors' contributions}

LB was involved in the design of the work, data analysis and interpretation and drafting the article. JVB was involved in the design of the work, the data interpretation and the critical revision of the article. EtP was involved in the critical revision of the article. MK was involved in the data collection and the critical revision of the article. NvD was involved in the design of the work, the data analysis and interpretation, the drafting of the article and the critical revision of the article. All authors read and approved the final manuscript.

\section{Competing interests}

The authors declare that they have no competing interests.

\section{Consent for publication}

Not applicable.

\section{Ethics approval and consent to participate}

At the start of the e-learning program, participants were informed about the possibility to participate in a study concerning the effectivity of the e-learning program. Participants could decide themselves whether or not to participate in the study before starting the e-learning program. Participants were informed that participation in the study had no influence on their educational program, participation was fully voluntary and data were processed anonymously. Electronically written informed consent (positive answer to digital questions on consent) was obtained from all participants.

According to Dutch law (Medical Research Involving Human Subjects Act (WMO)), based on the declaration of Helsinki, no ethical approval was required for this study as no patients were involved in the study.

\section{Publisher's Note}

Springer Nature remains neutral with regard to jurisdictional claims in published maps and institutional affiliations.

\section{Author details}

'Department of General Practice, Academic Medical Centre-University of Amsterdam, Meibergdreef 9, Amsterdam 1105 AZ, The Netherlands. 2Department of General Practice, Academic Medical Centre-University of Amsterdam, STI Aids Netherlands (Soa Aids Nederland), Meibergdreef 9, Amsterdam 1105 AZ, The Netherlands. 'Department of Educational Support, Academic Medical Centre-University of Amsterdam, Meibergdreef 9, Amsterdam 1105 AZ, The Netherlands. ${ }^{4}$ Dutch College of General Practitioners (Nederlands Huisartsen Genootschap, NHG), Mercatorlaan 1200, Utrecht 3528 BL, The Netherlands.

\section{Received: 21 November 2016 Accepted: 30 March 2017}

\section{Published online: 24 April 2017}

\section{References}

1. Trienekens SCM, Koedijk FDH, van den Broek IVF, Vriend HJ, Op de Coul ELM, van Veen MG, van Sighem Al, Stirbu-Wagner I, van der Sande MAB. Sexually transmitted infections, including HIV, in the Netherlands in 2011. In: National institute for public health and the environment. 2012.

2. CDC fact sheet: Reported STDs in the United States [http://www.cdc.gov/ std/stats14/std-trends-508.pdf]

3. Control ECfDPa. Sexually transmitted infections in Europe. Stockholm: European Centre for Disease Prevention and Control; 2014. p. 1-110.

4. Sexually Transmitted Infections (STIs); Fact sheet no 110. [http://www.who. int/mediacentre/factsheets/fs110/en/]
5. Workowski KA, Berman S. Sexually transmitted diseases treatment guidelines, 2010. In: Centers for disease control and prevention. 2010. p. 1-110.

6. Wimberly YH, Hogben M, Moore-Ruffin J, Moore SE, Fry-Johnson Y. Sexual history-taking among primary care physicians. J Natl Med Assoc. 2006; 98(12):1924-9.

7. Mulvey G, Keogh LA, Temple-Smith M. Outcomes of an educational activity with Victorian Ps aimed at improving knowledge and practices in relation to sexually transmissible diseases. Aust N Z J Public Health. 2000;24(1):76-8.

8. Davis N, Davis D, Bloch R. Continuing medical education: AMEE Education Guide No 35. Med Teach. 2008;30(7):652-66.

9. Fordis M, King JE, Ballantyne CM, Jones PH, Schneider KH, Spann SJ, Greenberg SB, Greisinger AJ. Comparison of the instructional efficacy of Internet-based CME with live interactive CME workshops - A randomized controlled trial. Jama-J Am Med Assoc. 2005;294(9):1043-51.

10. Rosenberg MJ. E-learning: strategies for delivering knowledge in the digital age. New York: McGraw-Hill; 2001.

11. Ruiz JG, Mintzer MJ, Leipzig RM. The impact of e-learning in medical education. Acad Med. 2006;81(3):207-12.

12. Ward JP, Gordon J, Field MJ, Lehmann HP. Communication and information technology in medical education. Lancet. 2001;357:792-6.

13. Domino FJ, Chopra S, Seligman M, Sullivan K, Quirk ME. The impact on medical practice of commitments to change following CME lectures: a randomized controlled trial. Med Teach. 2011;33(9):e495-500.

14. Dolcourt JL. Commitment to change: a strategy for promoting educational effectiveness. J Contin Educ Health Prof. 2000;20(3):156-63.

15. Pereles L, Lockyer J, Hogan D, Gondocz T, Parboosingh J. Effectiveness of commitment contracts in facilitating change in continuing medical education intervention. J Contin Educ Health Prof. 1997;17:27-31.

16. Mazmanian PE, Mazmanian PM. Commitment to change: theoretical foundations, methods, and outcomes. J Contin Educ Health Prof. 1999;19:200-7.

17. Van den Broek IVF, Verheij RA, van Dijk CE, Koedijk FDH, Van der Sande $M A B$, van Bergen JEAM. Trends in sexually transmitted infections in the Netherlands, combining surveilance data from general practices and sexually transmitted infection centers. BMC Fam Pract. 2010;11(39):1-8.

18. Van den Broek IVF, van Aar F, van Oeffelen AAM, op de Coul ELM, Woestenberg PJ, Heijne JCM, den Daas C, Hofstraat SHI, Hoenderboom BM, van Wees D, et al. Sexually transmitted infections in the Netherlands in 2015. In: National institute for public health and the environment (RIVM). 2016.

19. Organisatie \& Beleid [https://www.nhg.org/organisatie]

20. E-PIN "Het soa-consult" [https://www.nhg.org/winkel/producten/het-soaconsult-pin-171]

21. NHG: Programmaplan PIN "Het soa-consult". In.

22. Programma's voor Individuele Nascholing en Competentiegericht Leren [https://www.nhg.org/sites/default/files/content/nhg_org/uploads/ infotaakgebieden.pdf].

23. van Duin BJ, Nijholt AJ, Maiburg HJS. Werkgroep Actualisering Eindtermen en Competenties. In: Huisartsopleiding Cvd, editor. Competentieprofiel en eindtermen voor de huisarts. 2009.

24. Frank JRE. The CanMEDS 2005 physician competency framework. Better standars. Better physicians. Better care. Ottawa: The Royal College of Physicians and Surgeons of Canada; 2005.

25. Veelgestelde vragen NHG portal. [https://portal.nhg.org/mod/page/view. php?id=958] (in Dutch).

26. Lomas J. Words without words? The production, dissemination, and impact of consensus recommendations. Annu Rev Public Health. 1991; $12: 41-65$.

27. Fowkes FGR, Roberts CJ. Introducing guidelines into clinical practice. Eff Health Care. 1984;1:313-21.

28. Geertsma RH, Parker RC, Whitbourne SK. How physicians view the process of change in their practice behavior. J Med Educ. 1982;57:752-61.

29. Van Bergen JE, Dekker J, Broeke A, Kronenberg E, van der Spruit R, Bouma M, Verlee E. NHG-standaard Het soa-consult. Eerste Herziening Huisarts Wet. 2013;56(9):450-63

30. Paice $E$, Heard $S$, Moss F. How important are role models in making good docters? BMJ. 2002;325:707-10

31. Wear D. On white coats and professional development: the formal and hidden curricula. Ann Intern Med. 1998;129(9):734-7.

32. Jochemsen van derLeeuw $R$, van Dijk $N$, van Etten Jamaludin FS, Wieringa de Waard $M$. The attributes of the clinical trainer as a role model: a systematic review. Acad Med. 2013;88(1):26-34.

33. Corporation I: IBM SPSS statistics. In., 22.0 edn. 2013. Armonk, New York. 
34. Temple-Smith M, Mulvey G, Keogh L. Attitudes to taking a sexual history in general practice in Victoria, Australia. Sex Transm Infect. 1999;75:41-4.

35. Hinchliff S, Gott M, Galena E. 'I daresay I might find it embarrasing': general practitioners perspectives on discussing sexual health issues with lesbian and gay patients. Health Soc Care Community. 2004;13(4):345-53.

36. Parish SJ, Clayton AH. Sexual medicine education: review and commentary. J Sex Med. 2007;4:259-68.

37. Cantoni V, Cellario M, Porta M. Perspectives and challanges in e-learning: towards natural interaction paradigms. J Vis Lang Comput. 2004;15:333-45.

38. Zhang D, Zhou L, Briggs R, Nunamaker Jr J. Instructional video in e-learning: Assessing the impacto of interactive video on learning effectiveness. Inf Manage. 2006;43:15-27.

39. Cruess SR, Cruess RL, Steinert Y. Role modelling-making the most of a powerful teaching strategy. BMJ. 2008;336:718-21.

40. Kelman HC. Compliance, identification, and internalization: three processes of attitude change. J Conflict Resolut. 1958;2(1):51-60.

41. Donaldson SI, Grant-Vallone EJ. Understanding self-report bias in organizational behavior research. J Bus Psychol. 2002;17(2):245-60.

Submit your next manuscript to BioMed Central and we will help you at every step:

- We accept pre-submission inquiries

- Our selector tool helps you to find the most relevant journal

- We provide round the clock customer support

- Convenient online submission

- Thorough peer review

- Inclusion in PubMed and all major indexing services

- Maximum visibility for your research

Submit your manuscript at www.biomedcentral.com/submit
Biomed Central 